\title{
Estimating the Output Gap for Saudi Arabia
}

\author{
Ryadh M. Alkhareif ${ }^{1}$, William A. Barnett ${ }^{2} \&$ Nayef A. Alsadoun ${ }^{3}$ \\ ${ }^{1}$ International Monetary Fund, USA \\ ${ }^{2}$ University of Kansas, and Center for Financial Stability, USA \\ ${ }^{3}$ Saudi Arabian Monetary Authority, Saudi Arabia \\ Correspondence: Ryadh M. Alkhareif, International Monetary Fund, Washington, DC 20431, USA. Tel: \\ 1-202-623-7288. E-mail: ralkhareif@imf.org
}

Received: January 3, 2017

Accepted: January 21, 2017

Online Published: February 15, 2017

doi:10.5539/ijef.v9n3p81

URL: http://dx.doi.org/10.5539/ijef.v9n3p81

\begin{abstract}
The objective of this paper is to estimate annual potential output growth and the output gap for the Saudi economy over the period 1980 to 2015 , looking at both total output and non-oil output. The focus on the latter is so that the progress in diversifying the economy might be examined and the possible impact of diversification on potential output might be measured. We use three methods for estimating potential output proposed in the macroeconomic literature. The methodologies include the Hodrick-Prescott filter, Kalman filter, and the production function approach. We compare the three over the entire sample and the last five years. Our findings suggest that the output gap (the difference between actual and potential output, as measured by real GDP) is positive on average over the entire period (i.e., actual output has on average exceeded potential); however, the gap has turned negative and has shrunk in recent years, as fiscal expenditures, particularly in infrastructure, have acted to better align actual and potential. Our analysis also indicated that growth in both potential GDP and total factor productivity have accelerated in the 2011-2015 period. In contrast, growth in these factors has slowed in many other countries, particularly the advanced economies. This better performance of the Saudi economy is possibly due to the development of a resilient financial sector in the Saudi economy.
\end{abstract}

Keywords: potential output, output gap, total factor productivity, and inflation

\section{Introduction}

On the back of a prudent mix of macroeconomic policies and solid fundamentals supported by sizeable fiscal buffers and resilient financial system, the Saudi economy has indeed weathered a number of challenges in recent years, including the commodity price shock and episodes of financial turbulence impacting emerging markets. The Saudi government has also embarked ambitious reform agenda to achieve higher economic diversification and stronger medium-term growth, by increasing the flow of private investment, promoting competitiveness, and bolstering job creation. There is also a focus toward implementing a number of structural reforms underpinned by Vision 2030 and the National Transformation Program (NTP) to transform the Saudi economy towards a more efficient and diversified economy, while preserving macroeconomic stability and enhancing prospects for higher and more inclusive growth.

A number of key reforms outlined in the NTP focus on improving business environment and increase the role of the private sector in the economy specially the small and medium enterprises sector, by focusing on privatization and public-private partnerships with a view to develop local capital markets and encourage greater inflows of foreign direct investment (FDI). To boost employment of nationals, the Saudi government continues to focus on improving the education system, reducing skills mismatches, and shifting employment from the public to the private sector. The NTP seeks to encourage private sector employment of Saudi nationals and increase labor force participation while facilitating SMEs' access to finance in order to achieve the goal of higher, sustained, and job-creating growth.

Economic policies in Saudi Arabia also highlight the government's commitment to advance structural fiscal reforms to pursue steady fiscal consolidation and increase the efficiency of public investment, including by focusing on the most productive sectors while enhancing social safety nets. According to the Fiscal Balance Program, Saudi Arabia plans to eliminate the overall fiscal deficit by 2020 and ensure that the public debt remains at sustainable levels over the medium term while protecting the most vulnerable segments. In this regard, 
the government's recent announcement of establishing the Household Allowance Program is a step in the right direction to ensure stronger social safety net.

On monetary and exchange rate policy, safeguarding macroeconomic and financial stability is a key role for the Saudi Arabian Monetary Authority (SAMA). The current exchange rate peg to the U.S. dollar is considered to be an optimal choice for Saudi Arabia given the current structure of its economy. The fixed exchange rate regime has served Saudi Arabia well over the past three decades and remains appropriate (see Alkhareif \& Qualls, 2016 for more details about exchange rate policy in Saudi Arabia). SAMA took a number of measures to strengthen the regulatory framework, preserve financial stability, and promote soundness of the banking system while focusing on maintaining sufficient reserves to cushion against external shocks and anchor the exchange rate. Currently, all Saudi banks are fully compliant with Basel III regulations. The overall financial system has been resilient in spite of the protracted decline in oil prices, supported by large capital and liquidity cushions and high standards of regulation and supervision. The recent establishment of the National Financial Stability Committee (NFSC) is a step in the right direction to coordinate policy decisions among relevant agencies on systemic risk analysis and management.

Although structural reforms are likely to have a negative short-term effect on growth, employment, and inflation, such reforms are expected to deliver stronger growth over the medium term. In this regard, policymakers at the Kingdom would naturally be interested in analyzing the macroeconomic cycles to determine whether the economy is entering into an overheating phase or headed toward economic activity slowdown - and thereby react accordingly. Thus, the main goal of this paper is to provide reliable estimates of potential output and output gap for Saudi Arabia with a view to offer policymakers with additional tools at their disposal when viewing the business cycles.

Potential output can be defined as the maximum sustainable level of output, given full utilization of all factors of production, under conditions of stable inflation. In other words, it is considered to be the level of output that can be achieved by the economy at a constant inflation rate if all its resources were fully employed. While this paper focuses on the Saudi economy, it has been argued that oil exporting countries, GCC countries in particular, have among the world's highest non-oil potential growth (see Mitra, Hosny, Abajyan, \& Fischer, 2015). The Saudi economy, along with other GCC countries, has enjoyed strong growth over the past decade on the back of high oil prices and expansionary government fiscal policy for economic development. Inflationary pressures have emerged and presented a challenge to economic welfare.

Recently economic growth has weakened with the recent fall in oil prices, indicating a possible widening of the gap between potential and actual output, particularly for the non-oil private sector. However, lower oil prices may also lower potential growth because of lower levels of capital investment, due to less government oil revenue for infrastructure development. In addition, the Saudi government has initiatived major labor market reforms, which have a direct impact on the supply of expatriate labor. Under these circumstances, the lower oil prices and their impact on economic activity might present a challenge, especially given the high unemployment rate among Saudi nationals. However, the major education initiatives over the past decade are resulting in a better match of the skills of the young Saudi labor force, which would tend to counter the negative aspects.

In order to analyze the impact of these various factors on the Saudi economy, it is necessary to estimate both the potential output of the Saudi economy and the gap between the actual output and this potential. The study estimates potential output using Hodrick-Prescott filter, Kalman filter, and the production function methodologies. The sample period is annual from 1980 to 2015. The paper is structured as follows. Section two gives a brief on the importance of estimating potential output and output gap. The third section provides a review of the main estimation methodologies used in the literature and paper. Section four presents the results, and the final section concludes and discusses policy implications.

\section{Estimating Potential Output and Output Gap}

There has been an increasingly growing interest in measuring potential GDP and output gaps, with a number of studies focusing on the estimation of output gaps in the GCC including Ali and Mim (2011), Dupasquier, Guay, and St-Amant (1999), Osman (2011), and Osman, Louis, and Balli (2008). Potential output is determined by the supply side of the economy (i.e., the factors of production, such as capital stock, labor force and technology). It is determined by trend growth in the supply of both labor and capital, combined with how efficiently these factors of production can be utilized (i.e., total factor productivity). In the short run, fluctuations in aggregate demand can lead to significant deviations in actual real output (both positive and negative) from potential output. However, in the long run, actual economic output will show the same trend growth as will potential output. Estimating potential output is an important exercise, particularly for fiscal and monetary policy makers. The 
importance of estimating potential output reflects its critical role in understanding the determinants of economic growth, planning fiscal and budgetary policies, and anticipating inflationary dynamics and measurement. From a monetary policy standpoint, knowing potential output is crucial in order to strike a balance between output and inflation. Positive output gaps (i.e., where actual output exceeds potential) are typically associated with excess demand in goods and labor markets and increasing inflation, either actual or expected. Under these circumstances, central banks, particularly those targeting interest and/or inflation rates, will need to adopt contractionary policies. Policy coordination with the government to reduce domestic demand can complement monetary policy. If there is a negative output gap and inflation is low, then expansionary monetary policy, coordinated (if needed) with fiscal policy, can return the economy to its potential.

Recently, central banks have become more transparent in effectively and credibly communicating monetary policy. As a result, most inflation-targeting central banks now regularly publish estimates of their country's output gap along with inflation expectations. However, there are others who claim that the relationship between an individual country's output gap and inflation has weakened due to the increasing globalization and trade and economic openness of countries around the world (see e.g., Romer, 1993; Loungani, Razin, \& Yuen, 2001).

Despite the importance of estimating potential output and the output gap, there has been little research into this subject for Saudi Arabia and the GCC region in general. This is partially due to the difficulties in measuring potential output for countries that are dependent on oil exports, where a substantial portion of their real economic growth is determined by their actual oil production. Furthermore, for the GCC countries that are OPEC members, their actual oil production at any point in time is largely determined by strategic decisions that have little to do with the "potential output" of their oil sectors; rather, it is determined by world oil supply and demand conditions. For these countries, it would make more sense to look at the potential output of the non-oil sector, where there is a closer correlation between actual and potential output at any point in time. The oil sectors of their economies interact with the non-oil sectors primarily through the governments' spending of oil revenues on local goods and services and on the salaries of government workers.

The main contribution of this paper is twofold. To our knowledge, this is the first paper to estimate potential output for Saudi Arabia using the new series of the national accounts published by the General Authority for Statistics (GASTAT), as the base year has been updated. As indicated by the IMF, the revised GDP data are more comprehensive in terms of coverage of services, but has surly affected relative contributions by economic activity to GDP. Therefore, using the new series of the national accounts will provide policymakers with more accurate assessment of economic activity in the Kingdom. Second, the paper uses a bundle of estimation methods (statistical methods and production function method) to derive accurate estimates of potential output in Saudi Arabia, compared to other papers in this field that only focus on statistical methods, partly due to data limitation.

\section{Review of Methodologies}

Potential output and the output gap are economic concepts that are not actually observed. Their actual measurement is subject to a considerable amount of debate (see e.g., Chagny \& Döpke, 2001; Cotis, Elmeskov, \& Mourougane, 2004; and Orphanides, Porter, Reifschneider, Tetlow, \& Finan, 2000) for more information regarding the output gap estimation methods widely used in the literature). Different estimation methodologies have been devised to divide output into trend and cyclical growth components. The most widely used methodologies are based on either statistical approaches that use various time series analysis and decomposition techniques or econometric approaches that employ production functions. Below we describe the different methods: Hodrick-Prescott filter, Kalman filter, and the production function (Note 1).

\subsection{Hodrick-Prescott (HP) Filter}

The Hodrick-Prescott (HP) filter is one of the most commonly used technique due to its simplicity and flexibility. It is normally used to smooth output fluctuations by extracting the trend component, in which a tradeoff is made between a good fit to the actual data series and the degree of smoothness of the trend series (see Nelson \& Kang, 1981; and Mitra, Hosny, Abajyan, \& Fischer, 2015). The HP filter minimizes the difference between actual and potential output as follow:

$$
\sum_{t=1}^{T}\left(y_{t}-y_{t}^{*}\right)^{2}+\gamma \sum_{t=2}^{T-1}\left\lceil\left(y_{t+1}^{*}-y_{t}^{*}\right)-\left(y_{t}^{*}-y_{t-1}^{*}\right)\right]^{2}
$$

where $\gamma$ is a weighting factor that determines the degree of smoothing of the trend. A low value of $\gamma$ produce a trend output that follows actual output more closely. A high value, on the other hand, reduces the sensitivity of 
output trend to short-term fluctuations in actual output.

The simplicity and flexibility of the HP filter makes it an ideal tool for research involving emerging and developing countries, where data present a major challenge. On the negative side, statistical filters are purely statistical, and hence lack any economic intuition (i.e., statistical filters are not based on economic theory), as for instance indicated Kuttner (1994). In addition, statistical filters are not usually suitable for capturing high output volatility that is common in commodity exporting countries. For this reason, the HP filter estimate is a complement to the Kalman filter.

\subsection{Kalman Filter}

The Kalman filter model can be simply explained by two types of processes, known as the measurement equation and transition (state) equation (see Hamilton, 1994 for more details). The measurement and transition equations are defined respectively as following:

$$
\begin{gathered}
y_{t}=\beta_{t} x_{t}+\varepsilon_{t} \\
x_{t}=T_{t} x_{t-1}+G_{t} u_{t}
\end{gathered}
$$

where $y_{t}$ is the observed process (actual GDP), $x_{t}$ represents the state vector, $\beta_{t}$ is the transformation matrix that maps $x_{t}$ into the measurement domain, $T_{t}$ is the state transition matrix, and finally $\varepsilon_{t}$ and $u_{t}$ are the error terms. In addition, we assume that the error terms $\varepsilon_{t}$ and $u_{t}$ are independent and normally distributed with zero means and covariance matrices $R_{t}$ and $Q_{t}$ (we refer to Barnett and Alkhareif, 2013 for additional assumptions and details):

$$
\left[\begin{array}{l}
\varepsilon_{t} \\
u_{t}
\end{array}\right] \sim N\left(0,\left[\begin{array}{cc}
R_{t} & 0 \\
0 & Q_{t}
\end{array}\right]\right)
$$

\subsection{The Production Function Method}

The production function method describes the supply side and shows the relationship between output and its factor inputs (see Solow, 1955, 1956, 1957 \& Swan, 1956 for more details about the background of this method). Potential output is represented by a combination of factors: the inputs, labor and capital, multiplied by total factor productivity (Note 2). The assumptions are based on economic theory and commonly described using the Cobb-Douglas specification:

$$
Y_{t}=A_{t} L_{t}^{1-\alpha} K_{t}^{\alpha}
$$

here $Y_{t}$ is actual output in period t, $L$ is the labor that is employed as input, $K$ is the capital stock, A is the total factor productivity (TFP), and $\alpha$ is the share of capital in the national economy. We assume $\alpha=2 / 3$, as capital stock is certainly playing a prominent role in the Saudi economy. An improvement in total factor productivity is associated with a more efficient use of labor and capital, thus resulting in higher output. TFP is unobservable; therefore we calculate it by taking out the contribution of labor and capital to actual output as follow:

$$
A_{t}=\frac{Y_{t}}{L_{t}^{1-\alpha} * K_{t}^{\alpha}}
$$

Compared with the various statistical approaches, the production function is considered to be a better option in that it overcomes the statistical approaches' drawbacks. This is because production function estimates are more transparent, consistent over time, and conform to economic theory (see Cotis, Elmeskov \& Mourougane, 2004 for more details). However, the need for reliable data is a major drawback of the production function methodology, particularly in its application to developing countries. As specified $\mathrm{K}$ and L appear individually homogeneous. Most modelers try to adjust for (average) educational attainment and skills where data are available. Also, in this specification A (total factor productivity), affects $\mathrm{K}$ and L proportionately. Technology may also affect these two inputs non-homogenously. In addition, A can be strongly influenced by institutions (governance and market orientation) and absorptive capacity of capital accumulation and technology.

Box 1. Computational exercise

The following standard Cobb-Douglas form of the production function is applied:

$$
Y_{t}=A_{t} * K_{t}^{\alpha} * L_{t}^{(1-\alpha)},
$$

where $Y_{t}$ represents real GDP in period $t, K_{t}$ is the stock of capital, $L_{t}$ is the labor force, $A_{t}$ represents TFP, and $\alpha$ is the share of capital in output. 
The following steps are applied to estimate potential GDP:

1. Obtain historical TFP using the formula:

$$
A_{t}=\frac{Y_{t}}{K_{t}^{\alpha} * L_{t}^{(1-\alpha)}}
$$

2. Apply the HP filter to L, and A, which gives the trends of each variable.

3. Derive potential growth by applying trend L, and A to the Cobb-Douglas production function.

4. Calculate the growth rates of potential output.

\section{Results for the Estimation of Potential Output and Non-Oil Output}

Table 1 shows the average estimated potential GDP growth for Saudi Arabia over the period 1980-2015 and over the last five years using the different methodologies. The findings suggest that the average estimated potential GDP growth is 2.4 percent, higher than the average actual GDP growth of 2.2 percent. However, during the last five years where massive government spending took place, the average estimated potential GDP growth at 3.9 percent is below the average actual GDP growth of around 5 percent.

Table 1. Average estimated potential GDP growth

\begin{tabular}{lcc}
\hline Estimation Method & $1980-2015$ & $2011-2015$ \\
\hline HP Filter & $2.2 \%$ & $4.3 \%$ \\
Kalman Filter & $1.1 \%$ & $2.9 \%$ \\
Cobb Douglas & $4.1 \%$ & $4.5 \%$ \\
Average & $\mathbf{2 . 4 \%}$ & $\mathbf{3 . 9 \%}$ \\
\hline
\end{tabular}

Source: Authors estimations.

Unfortunately, the various approaches showed widely different estimates of productivity growth, suggesting that there may be problems with the data used in this analysis. This is undoubtedly due to the large contribution of the oil sector to total output, which is affecting the accuracy of the statistical methods used (e.g., Hasan \& Alogeel, 2008 show that the large contribution of the oil sector in Saudi Arabia's output affects the accuracy of statistical methods). This conclusion is obvious when we consider that actual oil production throughout most of the 1980-2015 period was well below the 10 million barrels per day (mbd) capacity that was maintained over most of the period, increasing to $12.5 \mathrm{mbd}$ toward the end. This fact would make the various time series estimation techniques of little value in calculating potential output. Even the Cobb-Douglas production function approach would produce spurious results, considering that there was little relationship between the labor employed by the oil sector and the sector's output. Employment in this sector more than tripled over the 1980-2015 period, whereas the sector's crude oil output, which reached 9.9 mbd in 1980, was not exceeded until 2015, when it reached an estimated level of $10.2 \mathrm{mbd}$.

The analysis is much more straightforward if non-oil GDP is analyzed. Table 2 shows the results of applying the various methodologies to the time series. The average estimated potential growth was 5.1 and 6.0 percent over the periods 1980-2015 and 2011-2015, respectively (Table 2). The average actual non-oil GDP growth reached 4.8 and 6.1 percent for the corresponding periods. Hence, the non-oil sector was performing above its potential only during the sub-period from 2011-2015, and then only slightly. More importantly, all of the estimation methods showed relatively consistent and convergent values, indicating that the data being used are accurately measuring the actual relationship between the various inputs (i.e., capital and labor) and the real output of the non-oil sector.

Table 2. Average estimated potential non-oil GDP growth

\begin{tabular}{lcc}
\hline Estimation Method & $1980-2015$ & $2011-2015$ \\
\hline HP Filter & $4.6 \%$ & $6.0 \%$ \\
Kalman Filter & $4.9 \%$ & $5.9 \%$ \\
Cobb Douglas & $5.7 \%$ & $6.1 \%$ \\
Average & $\mathbf{5 . 1 \%}$ & $\mathbf{6 . 0 \%}$ \\
\hline
\end{tabular}

Source: Authors estimations. 
The acceleration in potential non-oil GDP growth over the last five years is a particularly encouraging development and is in sharp contrast to many countries, particularly those in the developed world, where potential GDP growth has slowed sharply. The positive development of the financial sector has also promoted financial stability and supported this healthy growth. A successful implementation of the NTP is expected to spur the potential growth, as it will further encourage the diversification of the Saudi economy and the development of the Kingdom's indigenous labor force.

In addition, the estimates above are in line with estimates in research on oil producers in the GCC. For instance, Mitra, Hosny, Abajyan, and Fischer (2015) estimated non-oil output for GCC countries to be around 7 and 6 percent for the period 2003-07 and 2008-14, respectively. The argument behind the GCC's high potential growth is due to the strong tie of non-oil sector to oil revenues and government spending.

Measuring productivity is of particular importance for policymakers. This paper shows that productivity in the overall economy has been negative during the period of 1980-2015, but positive during the period 2011-2015 (Table 3). The negative growth over the 1980-2010 period is primarily due to the impact of the decline in crude oil output combined with the tripling of employment in that sector which was mentioned earlier. It is also driven, in part, by major economic downturns associated with the 1980s oil glut, 1998 oil price decline, and the 2008 financial crisis. However, productivity in the overall Saudi economy recorded a 1.3 percent growth during the last five years on the back of higher government expenditure, massive infrastructure projects, and more importantly growing resilience of the financial sector. It was also aided by growth in Saudi oil production over that period.

Productivity growth for the non-oil sector has been positive at 1.6 and 2.5 percent for the periods 1980-2015 and 2011-2015, respectively. On the labor side, the last five years witnessed higher labor participation, which increased by more than 13 percent. The increase in the participation rate is partly due to labor market reforms, which indeed contributed to higher productivity. Capital expenditure, on the other hand, is certainly playing a prominent role in the Saudi economy and the stability of non-oil output. This is indicative of the relatively higher efficiency in the utilization of the factors of production in the non-oil sector of the economy. However, it should be noted that expansionary fiscal policy and capital expenditure may take time in order to translate into higher productivity as can be observed during the expansionary period from 2005 to 2007.

Table 3. Total factor productivity growth estimates

\begin{tabular}{lcc}
\hline & $1980-2015$ & $2011-2015$ \\
\hline Overall Economy & $-1.1 \%$ & $1.3 \%$ \\
Non-oil Sector & $1.6 \%$ & $2.5 \%$ \\
\hline
\end{tabular}

Source: Authors estimations.

The faster growth in total fact productivity mirrors the same pickup that was observed in potential GDP growth in Table 2. Again, this boost in productivity is in sharp contrast to the slowdown in other countries, particularly in the developed world. Much of this slowdown is undoubtedly due to the lingering effects of the financial crisis, which had little impact on the Saudi economy and its financial system, other than its transitory impact on world oil markets.

It is worth mentioning that the variation between the actual and potential real GDP growth rates has diminished in the past few years, in both the overall economy and the non-oil sector (Figures 1-2). As can be seen from the figures, the large drop in oil production during the mid-80s and again in the late 90 s is clearly captured. The discrepancy between the actual and potential real GDP growth widens the most during boom and bust cycles, mainly due to the impact of sudden movements in oil prices on the level of government spending and the economy as a whole. Over the last few years, the Saudi economy has been performing above its potential. The Saudi government has been able to counterbalance adverse oil price shocks by implementing countercyclical spending policies, due to the strong economic fundamentals the Kingdom currently possesses (e.g., strong financial buffers, low debt levels, a moderate inflation environment, and a resilient banking system). 


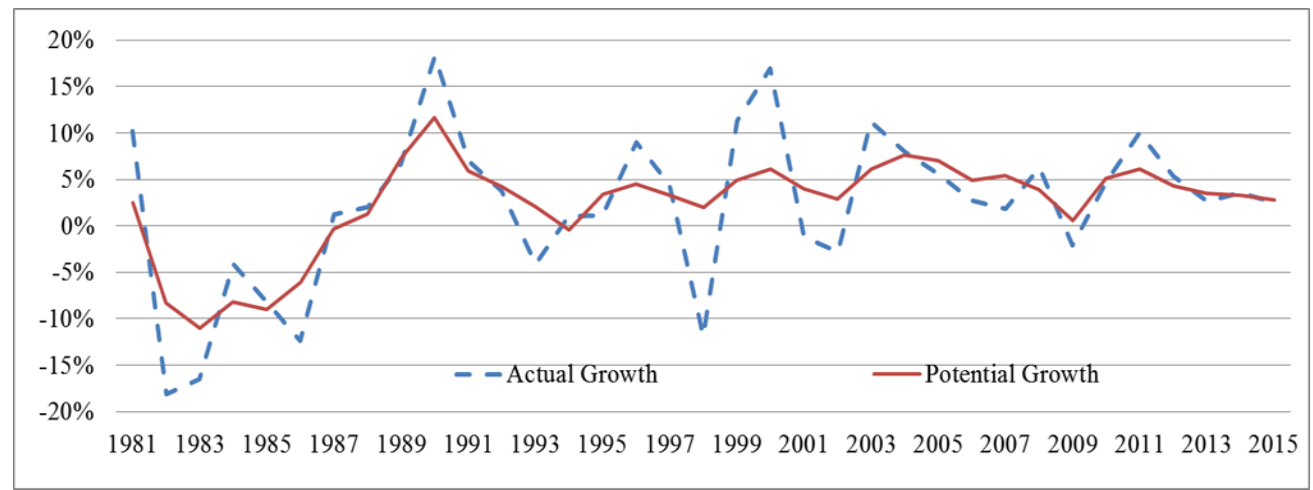

Figure 1. Real GDP growth (Actual vs. Potential)

Source: Central Department of Statistics and Information and authors' estimations.

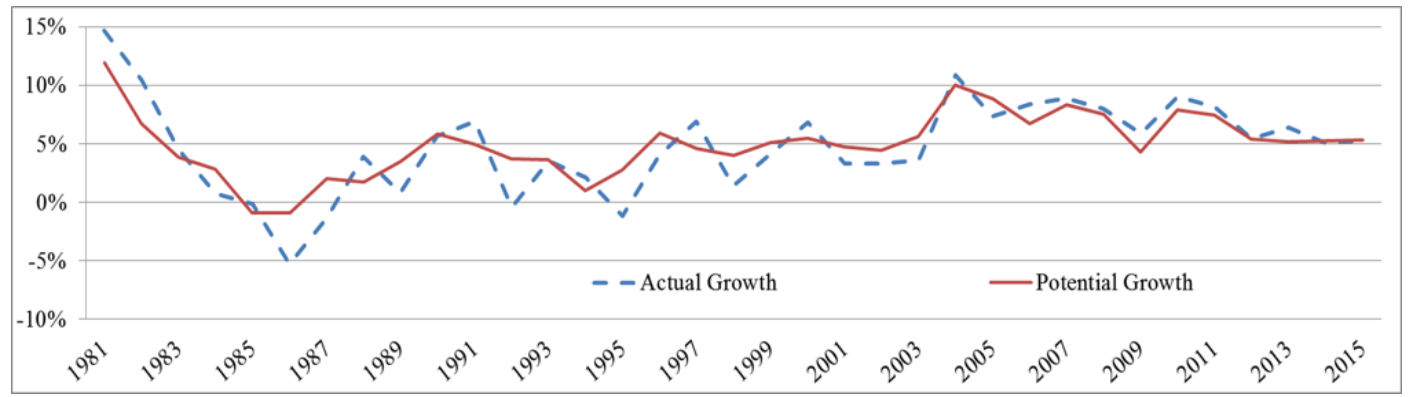

Figure 2. Real non-oil GDP growth (Actual vs. Potential)

Source: Central Department of Statistics and Information and authors' estimations.

Looking at the decomposition of real GDP growth for both the overall economy and the non-oil sector, it is clearly evident that the massive level of capital spending was a key driver for growth (Figures 3-4). The contribution of labor component, on the other hand, has been broadly limited for most of the period. Large increase in employment is associated with public sector, where contribution to growth is quite limited compared to that of private sector. Nonetheless, the labor component as well as the TFP have been the driving factors for growth over the past four years - in addition to the attentive labor market reforms that took place recently. These reforms were mainly targeted at boosting employment and competitiveness of nationals in the private sector with a view to achieve higher labor productivity.

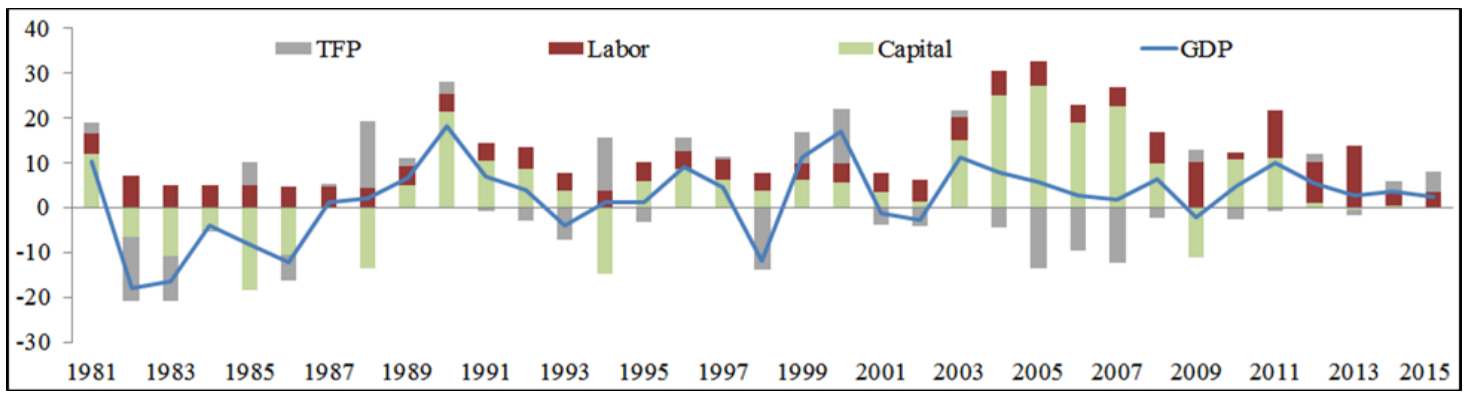

Figure 3. Real GDP growth decomposition

Source: Authors' estimations. 


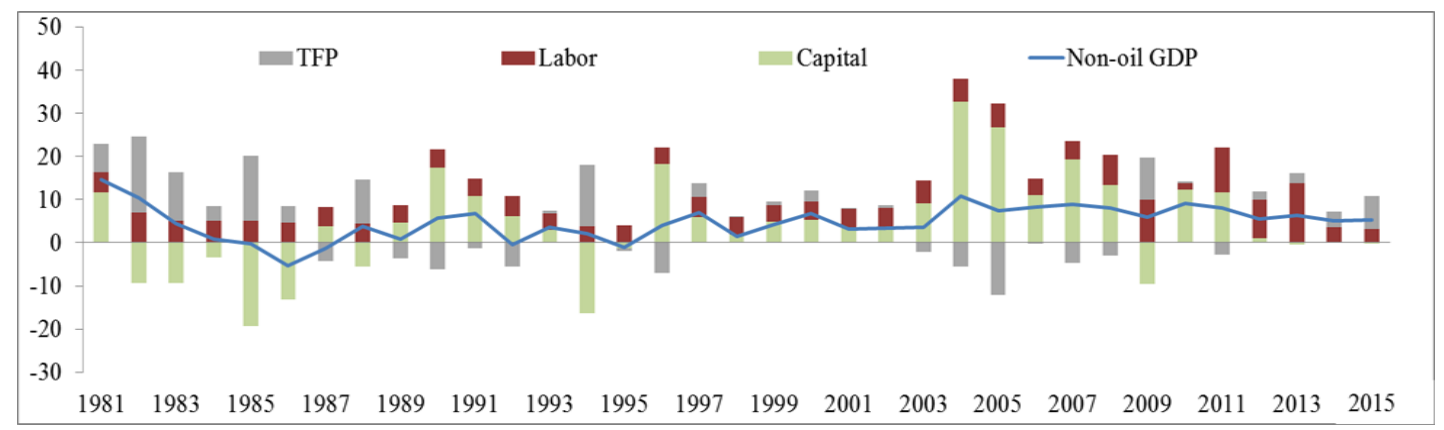

Figure 4. Real non-oil GDP growth decomposition

Source: authors' estimations.

Finally, we compute the output gap (i.e., the difference between the actual output and its estimated potential) for the overall economy and the non-oil sector in Saudi Arabia over the period of 1980-2015. It appears that the pattern of the gap is susceptible to movements in oil prices, as they affect oil revenues (Figures 5-6). For instance, the drop in oil prices during the early 1980s and in 1998 led to negative output gaps. The output gaps have shrunk substantially over the past five years, for both the overall economy and the non-oil sector, in conjunction with stable inflation rates. This implies that the Saudi economy is performing at a level close to its potential. Inflation, on the other hand, was around 2-3 percent. If we assume that output gap was close to zero at that period, an inflation rate between 2-3 would fit ideally within the comfort zone for the Saudi economy.

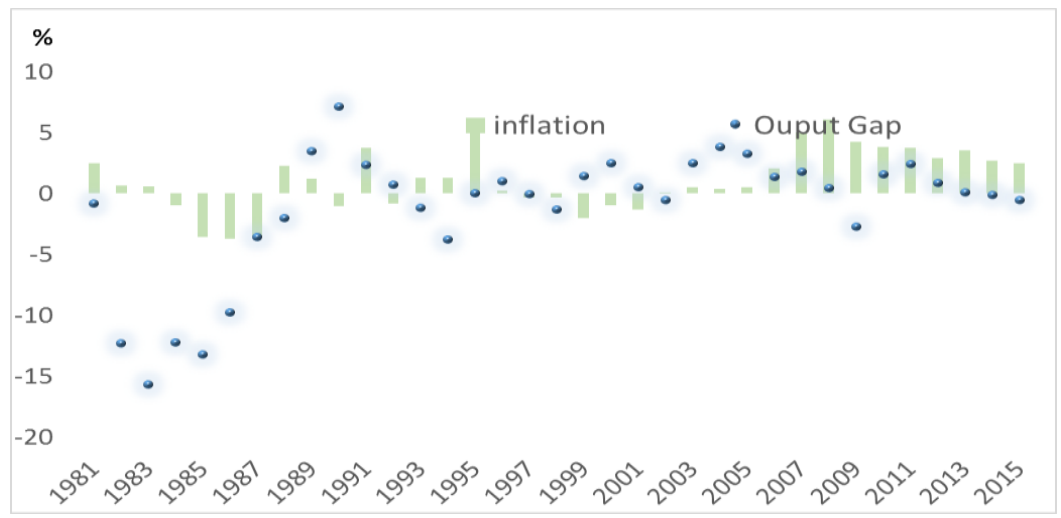

Figure 5. Inflation vs. output gap for the overall economy

Source: authors' estimations.

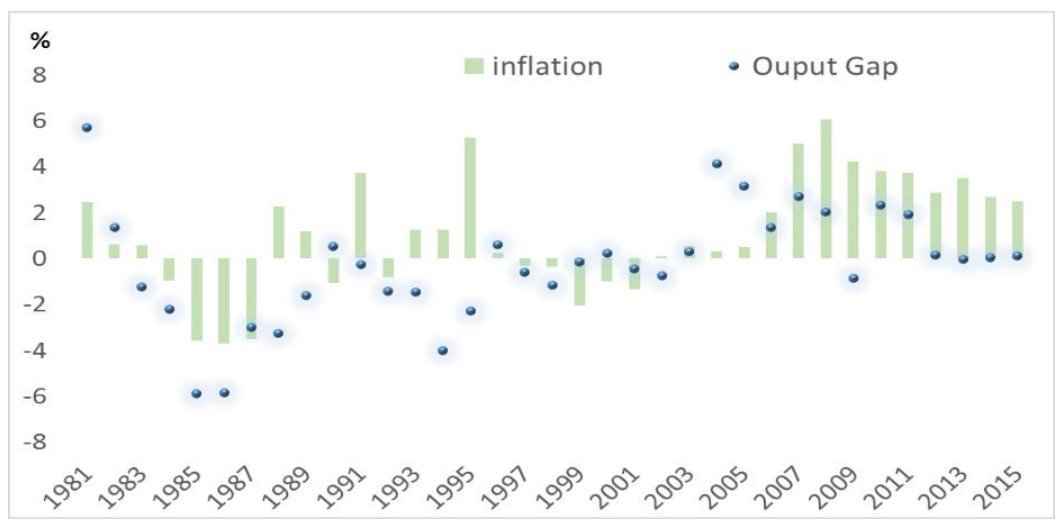

Figure 6. Inflation vs. output gap for the non-oil sector

Source: authors' estimations. 


\section{Conclusion and Policy Implications}

The Saudi government embarked ambitious reform agenda to achieve higher economic diversification and stronger medium-term growth, by increasing the flow of private investment, promoting competitiveness, and bolstering job creation. The ambitious reform goals announced in Vision 2030 and the NTP are timely and imperative. To achieve the Kingdom's overarching goal of transforming the economy towards a more efficient and diversified economy, policymakers will use to the extent possible all relevant economic indicators that provide useful information about the state of the economy and economic conditions in general. Therefore, measuring potential output is extremely valuable, particularly during periods of significant economic transformation.

This paper estimates the potential output and output gap for the Saudi economy using statistical and production function methodologies. The estimates vary based on selected approaches, which raise cautious about estimate uncertainty. Such estimate uncertainty is generally high in developing economies that experience volatile output growth. This call for further research on this area, especially for economies dependent on natural resource.

The estimates presented in this paper show that output gap, for both total and non-oil, have been positive on average, but turns negative and shrinking in recent years. The increase in fiscal expenditure has been vital for aligning actual output with that of potential output. However, a slowing pace of government expenditure could result in widening output gap. With respect to labor, policies should be aimed at improving labor market efficiency by increasing labor skills and participation in productive sectors. The Saudi economy would certainly benefit from investment in promoting a diversified economy that is less dependent on natural resources.

The analysis of this paper indicates that growth, in both potential GDP and total factor productivity, has accelerated in the 2011-2015 period. This is in sharp contrast to growth in other countries, particularly in the developed world. Much of this slowdown is probably due to the after effects of the 2008-2009 financial crisis, but had little effect on the Saudi economy. This can be attributed to the development of a resilient financial sector in the Saudi economy.

Future potential GDP growth might be adversely impacted by changes in the two major factors of output. Capital investment could be adversely affected by the decline in oil prices, which will cut government spending on infrastructure. However, such a condition will only be short-term in nature. The drive for Saudization of the workforce could create a labor shortage, but only if there is a continued mismatch of the skill set of Saudis versus the needs of the non-oil sector. Such a possibility is not thought to be likely though, since the educational initiatives over the past decade are resulting in a much better trained and younger workforce. This will have a positive impact on longer-term growth and productivity, if wisely planned.

\section{References}

Ali, M. S. B., \& Mim, S. B. (2011). What Drives Inflation in MENA Countries? International Journal of Economics and Finance, 3(4), 119. https://doi.org/10.5539/ijef.v3n4p119

Alkhareif, R. M., \& Qualls, J. H. (2016). Saudi Arabia's Exchange Rate Policy: Its Impact on Historical Economic Performance. Saudi Arabian Monetary Authority Working Paper 16/4, Riyadh.

Barnett, W. A., \& Alkhareif, R. M. (2013). Advances in Monetary Policy Design: Applications to the Gulf Monetary Union. Cambridge Scholars Publishing.

Chagny, O., \& Döpke, J. (2001). Measures of the output gap in the euro-zone: An empirical assessment of

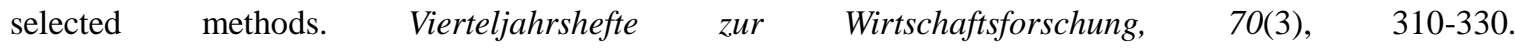
https://doi.org/10.3790/vjh.70.3.310

Cotis, J. P., Elmeskov, J., \& Mourougane, A. (2004). Estimates of potential output: benefits and pitfalls from a policy perspective. The euro area business cycle: stylized facts and measurement issues, Centre for Economic Policy Research, 35-60.

Dabla-Norris, M. E., Guo, M. S., Haksar, M. V., Kim, M., Kochhar, M. K., Wiseman, K., \& Zdzienicka, A. (2015). The new normal: A sector-level perspective on productivity trends in advanced economies. International Monetary Fund. https://doi.org/10.5089/9781498334181.006

Dupasquier, C., Guay, A., \& St-Amant, P. (1999). A survey of alternative methodologies for estimating potential output and the output gap. Journal of Macroeconomics, 21(3), 577-595. https://doi.org/10.1016/S0164-0704(99)00117-2

Hamilton, J. D. (1994). Time series analysis (Vol. 2). Princeton: Princeton university press. 
Harvey, A. C., \& Jaeger, A. (1993). Detrending, stylized facts and the business cycle. Journal of Applied Econometrics, 8(3), 231-247. https://doi.org/10.1002/jae.3950080302

Hasan, M. M., \& Alogeel, H. (2008). Understanding the inflationary process in the GCC region: The case of Saudi Arabia and Kuwait.

IMF Country Report. (2016). Saudi Arabia: Article Iv Consultation-Press Release; Staff Report; And Informational Annex. International Monetary Fund, No. 16/326.

Kuttner, K. N. (1994). Estimating potential output as a latent variable. Journal of Business \& Economic Statistics, 12(3), 361-368. https://doi.org/10.1080/07350015.1994.10524551

Loungani, P., Razin, A., \& Yuen, C. W. (2001). Capital mobility and the output-inflation tradeoff. Journal of Development Economics, 64(1), 255-274. https://doi.org/10.1016/S0304-3878(00)00132-2

Mitra, M. P., Hosny, A., Abajyan, G., \& Fischer, M. M. (2015). Estimating Potential Growth in the Middle East and Central Asia (No. 15-62). International Monetary Fund. https://doi.org/10.5089/9781475545364.001

Nelson, C. R., \& Kang, H. (1981). Spurious periodicity in inappropriately detrended time series. Econometrica: Journal of the Econometric Society, 741-751. https://doi.org/10.2307/1911520

Orphanides, A., Porter, R. D., Reifschneider, D., Tetlow, R., \& Finan, F. (2000). Errors in the Measurement of the Output Gap and the Design of Monetary Policy. Journal of Economics and Business, 52(1), 117-141. https://doi.org/10.1016/S0148-6195(99)00031-4

Osman, M. (2011). Potential output and output gap for the gulf cooperation council (GCC) countries: Alternative methods. Journal of Economic and Social Research, 13(2), 29.

Osman, M., Louis, R., \& Balli, F. (2008). Which Output Gap Measure Matters for the Arab Gulf Cooperation Council Countries (AGCC): The Overall GDP Output Gap or the Non-Oil Sector Output Gap?

Romer, D. (1993). Openness and inflation: Theory and evidence. The Quarterly Journal of Economics, 108(4), 869-903. https://doi.org/10.2307/2118453

Solow, R. M. (1955). The production function and the theory of capital. The Review of Economic Studies, 23(2), 101-108. https://doi.org/10.2307/2296293

Solow, R. M. (1956). A contribution to the theory of economic growth. The Quarterly Journal of Economics, 70(1), 65-94. https://doi.org/10.2307/1884513

Solow, R. M. (1957). Technical change and the aggregate production function. The Review of Economics and Statistics, 312-320. https://doi.org/10.2307/1926047

Swan, T. W. (1956). Economic growth and capital accumulation. Economic Record, 32(2), 334-361. https://doi.org/10.1111/j.1475-4932.1956.tb00434.x

\section{Notes}

Note 1. The General Authority for Statistics (GASTAT) is the main source of the data used in this paper, as it is the official authority responsible of providing data on Saudi Arabia. The analysis in this study is based on annual data from 1980 to 2015.

Note 2. The massive investments in human capital and education that took place over the past decade should enhance productivity of the young Saudi labor force and support medium-term growth. In this regard, using the Augmented Cobb-Douglas production function within which education is included as an explanatory variable seems appropriate. We recommend future research to follow this approach, once data become fully available.

\section{Copyrights}

Copyright for this article is retained by the author(s), with first publication rights granted to the journal.

This is an open-access article distributed under the terms and conditions of the Creative Commons Attribution license (http://creativecommons.org/licenses/by/4.0/). 